\title{
Natural hazard's effect and farmers' perception: Perspectives from flash floods and landslides in remotely mountainous regions of Vietnam
}

\author{
Nga Thanh Thi Pham ${ }^{\mathrm{a}, \mathrm{b}, *}$, Duy Nong ${ }^{\mathrm{c}}$, Matthias Garschagen ${ }^{\mathrm{d}}$ \\ a United Nations University, Institute for Environment and Human Security, Germany \\ b Thai Nguyen University of Agriculture and Forestry, Viet Nam \\ c Agriculture and Food, The Commonwealth Scientific and Industrial Research Organisation (CSIRO), Australia \\ d Ludwig-Maximilians-Universität München (LMU), Department of Geography, Germany
}

\section{H I G H L I G H T S}

- Farmers' cognition on flash floods and landslides in Vietnam is examined.

- Multinomial Logit models are used for investigating indigenous farmers' perceptions.

- Local farmers' awareness varies across different agro-ecological areas.

- Socioeconomic features are determining forces in explaining farmers' awareness.

- Findings can be the references for policy-making in regions with similar conditions.

\section{A R T I C L E I N F O}

\section{Article history:}

Received 5 May 2020

Received in revised form 24 September 2020

Accepted 25 September 2020

Available online 2 October 2020

Editor: Damia Barcelo

\section{Keywords:}

Perception

Flash floods

Landslides

Yen Bai province

Vietnam

Multinomial Logit model
G R A P H I C A L A B S T R A C T

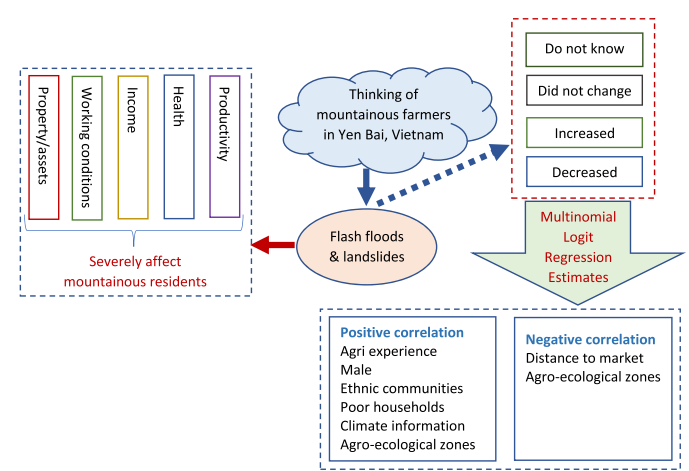

\begin{abstract}
A B S T R A C T
Understanding perceptions of indigenous people toward natural disasters is essential in social and environmental research to facilitate further studies in investigating the impacts of the events, as well as in examining the adaptive strategies and having implications for policymakers and relevant institutional bodies. We took this essential feature to study the perceptions of local people toward the two common natural disasters: flash floods and landslides. We selected the case study in three communes (An Binh, An Thinh, and Dai Son) in Van Yen district, Yen Bai province in Vietnam. This is because flash floods and landslides are two frequent natural disasters that highly adversely affect these areas where major poor ethnic minority communities reside. We conducted six Focus Group Discussions (FGDs) and household surveys (405 households) in 2016. The results showed that a decline in productivity, a decrease in income, more hard-working conditions, and an increase in daily expenses were the most observed impacts of these natural disasters in the communes. The analysis also revealed that almost $45 \%$ of farmers perceived an increasing trend in the frequency and impacts of flash floods and landslides over the past 15 years. A Multinomial Logit (MNL) model was used to analyze the determinants of farmers' awareness of flash floods and landslides, which indicated that farmers' perceptions of flash floods and landslides are associated with socio-economic characteristics, such as gender, agricultural experience, ethnic groups, climate information, and household income conditions. We suggested that local governments should pay more attention to strengthen farmers' awareness to help improve perceptions of local people toward common natural disasters so that they would gain better adaptive capacities and become more sustainable, which are in line with the Sustainable Development Goals.
\end{abstract}

(c) 2020 Elsevier B.V. All rights reserved.

\footnotetext{
* Corresponding author at: United Nations University, Institute for Environment and Human Security, Germany.

E-mail address: nga.pham@ehs.unu.edu (N.T.T. Pham).
} 


\section{Introduction}

Natural hazards and extreme weather events triggered by climate change have been threatening agricultural production and food security in many regions around the world (IPCC, 2018). They particularly threaten developing nations, of which a large population heavily relies on agricultural production as primary income sources (Deschenes and Greenstone, 2007; Porter et al., 2014). Agriculture-related households in these regions are becoming increasingly vulnerable due to low adaptive capacities and high exposures to natural disasters (Adger, 2003; Kates, 2000). In addition, being the foremost sustainable source of food and mainly depending on environmental conditions, agriculture is widely recognized to be one of the most affected sectors to climatic hazards in various ways (Das, 2005; Kurukulasuriya and Mendelsohn, 2006). For instance, increasing global warming causes decreased crop yields, increased livestock deaths, outbreak of insect pests, and diseases due to heat stress. Changes in precipitation, on the other hand, lead to increased frequency of droughts and floods, shift in crop growing season, and increase soil erosion resulting from intense rainfall and floods. Besides, increased sea-level causes loss of arable lands and salinization of irrigation water, particularly in the Pacific islands and Southeast Asian countries (FAO, 2015; Mendelsohn, 2008; World Bank, 2017). In such contexts, adaptation measures should be considered thoroughly to increase the resilience and adaptive capacity, to reduce the vulnerability at the farm level, and to secure rural livelihoods (Adger et al., 2009; Gbetibouo, 2009).

Yet, it is important to pinpoint that before individuals respond to climate variability, they in advance need to be aware of changes in the environment that would affect their production activities, livelihoods, and daily activities (Adger et al., 2009; Hasan and Kumar, 2019). Natural hazards not only affect social aspects, but also significantly impact environmental issues, such as soil erosion, landscape, land-use change, and related emissions. Hence, perceptions of local people toward natural hazards are essential to protect and improve the environment and people's social features. That is, people's perceptions will direct their adaptation actions on how they change their cropping patterns, crop variegation, crop management, and soil and plant protection. These actions have impacts on land-use change, landscape, soil quality, carbon release, and many other environmental features. People's living behaviors (changing living habits, moving to other places, or finding nonagricultural and forest-related jobs) against natural hazards due to their perceptions also affect the environment nearby because their impacts on natural resources will change. Consequently, perceptions can be considered to be the root of adaptation strategies, and the decision to undertake adaptation measures is strongly influenced by cognitive factors (Adger and Vincent, 2005; Grothmann and Patt, 2005). As a result, no appropriate adaptation or maladaptation to moderate the escalating adverse impacts of natural hazards might be resulted from misconceptions about climate trends and variability, as well as induced risks.

Against this background, various studies have used different methods to study farmers' cognitive processes subject to changes in environmental conditions. In particular, the determinants have been examined across different contexts and regions, for example, in Austria (Mitter et al., 2019), in Australia (Agho et al., 2010), in Bangladesh (Hasan and Kumar, 2019; Hasan and Kumar, 2020), in Pakistan (Abid et al., 2019), in Zimbabwe (Zamasiya et al., 2017), in Thailand and Vietnam (Cullen and Anderson, 2016; Le Dang et al., 2014; Waibel et al., 2018), in China (Pan, 2016); in South Africa (Gandure et al., 2013; Gbetibouo, 2009), in Ethiopia (Deressa, 2009), in Slovenia (Santoro et al., 2019), and in Germany and Zimbabwe (Grothmann and Patt, 2005). By conducting a case study in Punjab-Pakistan, Abid et al. (2019) suggested that local farmers' perception of climate variations is influenced by not only internal but also environmental factors, such as education, land holdings, ownership, cooperation, and geographical location. There is evidence, documented from a case study of an ethnic community in Himalaya, suggesting that gender and age are primary aspects in order to grasp how the local farmers acknowledged their attitudes subject to changes of climate (Sharma et al., 2020). Another exploration, carried out in Nigeria to investigate the climate variability perception among different economic sectors across the maize-poultry value chain, advocated that poultry and maize farmers are more likely to perceive changes in climate than feed millers and maize merchants (Liverpool-Tasie et al., 2020). Additionally, a crossEuropean analysis, deducted by Poortinga et al. (2019), has added political factors in understanding households' perception of changes in climatic events. These studies, however, only focused on understanding people's perceptions of climate-related events in general, not focusing on particular events caused by climate variabilities, such as flash floods and landslides. These specific natural hazards have been major problems in mountainous regions, particularly in steeply mountainous and highly deforested areas (MONRE, 2017). These natural disasters often happen intensively and quickly destroy agricultural production fields, houses, roads, public facilities, keeping people in these remote areas more isolated to receive external help (Marconi et al., 2011). People in such situations usually experience food shortages, lack of healthcare, and salvage in many days or weeks. Also, many households obviously lose their houses and production fields permanently after flash floods and landslides happened (Pham et al., 2019). Hence, understanding farmers' perceptions of flash floods and landslides obviously becomes one important aspect in environmental research with significant implications for many highly mountainous areas around the world.

The present analysis applies a quantitative approach to investigate not only how rural farmers in the Northern Mountainous Regions of Vietnam perceive changes in the frequency and impacts of flash floods and landslides but also which socio-economic variables at the household level might potentially explain individual perception process. In addition, by means of focus group discussions (FGDs) and in-depth interviews, this study identifies the major impacts of such natural hazards on the households' livelihoods. In view of the existing literature related to farmers' perception to climate change, which assumed that farmers' demographic profile, farmland characteristics, social networks, institutional attributes, and locational dimension might be highly relevant in understanding individuals' perception, this study further considers additional factors concerning the salient features of the research areas (ethnicity of the households' head and household conditions). Additionally, the topic of rural farmers' perception to such natural hazards (flash floods and landslides) has not yet received adequate attention and investigation globally. The knowledge on this aspect is still limited, as there is scarce empirical research underlying the drivers influencing farmers' perception of such flash floods and landslides.

The primary objective of this study is, therefore, to fill the gap in the existing literature on exploring variables potentially impacting how rural farmers perceive changes in flash floods and landslides by using the Multinominal Logit model. In other words, this objective has twofold.

- First, we select the base case (or the worst case) that some farmers are not aware of any changes in the frequency and impacts of flash floods and landslides. Then we examine how different factors (explanatory variables) affect farmers' perceptions that make them select the other options ('increased', 'decreased', or 'remained unchanged') relative to the base case. This would help us explain why local people have some brainstorming about the things happened around them rather than do not know anything so that relevant stakeholders will be able to help improve their perceptions by focusing on enriching the most influenced factors.

- Second, we investigate how factors drive farmers' perception in particular choice categories ('increased', 'decreased', 'remained unchanged', or 'do not know') so that we can understand the dominant factors in each option. Consequently, it would help promote their perceptions by focusing Government's implementation on these 


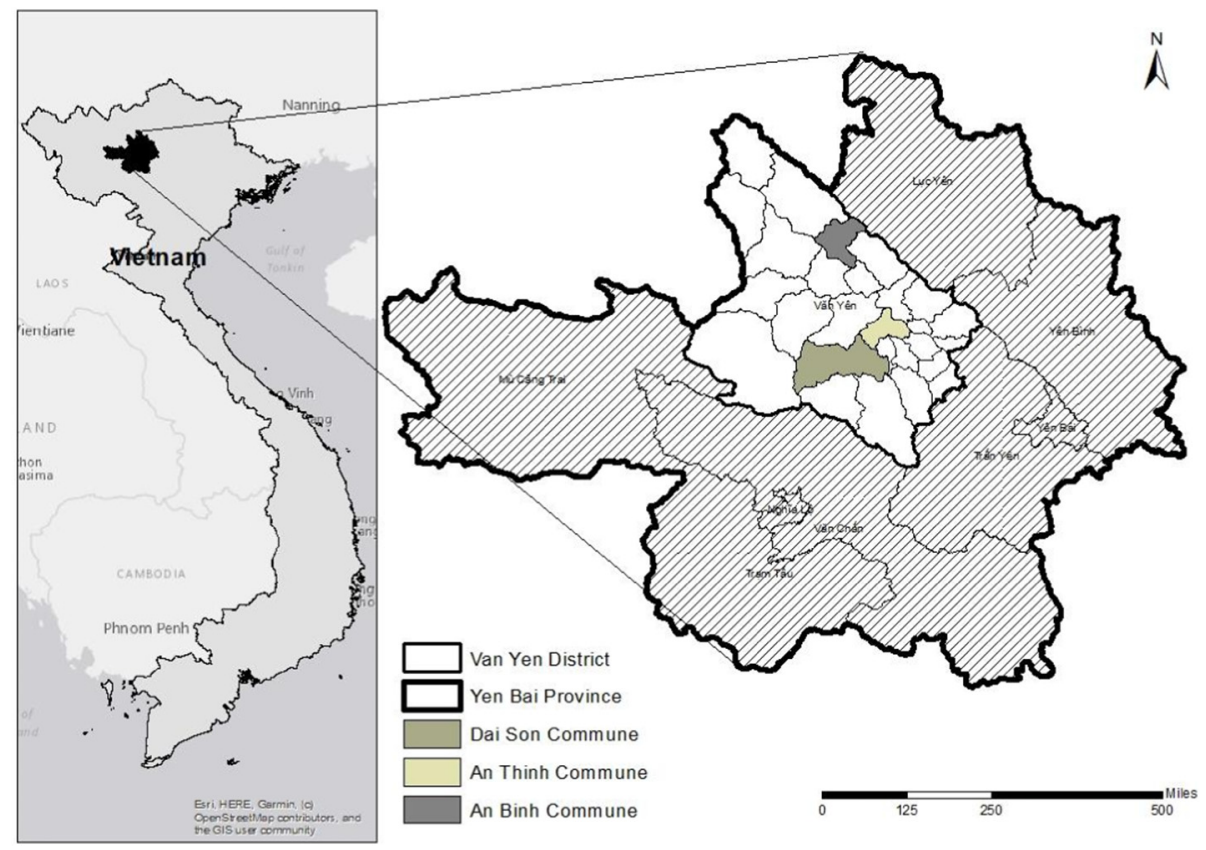

Fig. 1. Map of the study areas.

dominant factors, which would result in better directions for future policy strategies to help achieve sustainable development in the society.

We further attempt to draw out to what extent rural farmers have been affected by such natural hazards. Our case study is carried out in one of the most remotely and highly mountainous regions (Van Yen district, Yen Bai province in Vietnam), where many indigenous people reside (Do et al., 2013). According to the income level statistics, people living in this area have been regarded as extremely poor residents under the Program 135 announced by the Vietnamese Government, ${ }^{1}$ and their livelihoods mainly rely on agricultural production and forest collection. Local people also have low education levels and poor production facilities. Public infrastructures are also not well developed in the region. Yet, flash floods and landslides frequently happen intensively in the area, causing major livelihood problems on these indigenous residents.

The present study is useful in many different aspects, mainly reflecting how indigenous people perceive particular natural hazards frequently happening in their living areas so that local and state governments, as well as non-profit organizations, are able to help to improve their perceptions on how important to understand correctly and comprehensively the impacts of these natural hazards. It is to help not only people living in the study areas but also to assist residents in many other similarly geographic and socio-economic regions. The findings are also useful for designing appropriate policy measures to support farmers in selecting adaptation methods and become more resilient facing future natural hazards. In addition, to our knowledge, the research is the first attempt using econometric models to explore awareness of people regarding flash floods and landslides in Vietnam. Such investigations have significant contributions to elaborate further farmers' adaptive behaviors and protection motivation to climate variability and natural hazards at both national and local levels. Such findings may not only help policymakers have a holistic view of the impact of these disasters on people's livelihood activities but also assist them in identifying factors that need the interventions and supports

\footnotetext{
${ }^{1}$ http://csdl.ubdt.gov.vn/noidung/vanbandt/SiteAssets/Lists/UBDTVanBanDen/ EditForm/yenbai.pdf.
}

from local authorities in raising people's awareness. Thus, the findings of our study add to the growing literature on understanding individual cognition and further becoming helpful for designing effective development programs not only in the study areas but also in other regions with similar socio-economic and climate conditions.

The paper is structured in four sections. The material and methods of the research are presented in Section 2. We further discuss the main findings and results in Section 3. The conclusions and potential policy implications are finally provided in Section 4.

\section{Material and methods}

\subsection{Study area and household survey}

This study was conducted in Van Yen district situated in the North of Yen Bai province in Vietnam (Fig. 1). The province is located between the Northwest-Northeast and Midlands North of the country, which is characterized by rugged mountains rising from East to West and from South to North. Two main rivers are flowing through the province: The Red River and the Chay River (Marconi et al., 2011). In addition, Yen Bai has about 200 canals, small streams, large lakes, and swamps. The province's economy depends mainly on agriculture and forestry, with $79.4 \%$ of the labor force working in these sectors. In total, agricultural land makes up nearly $16 \%$ of the province's area, while $69 \%$ of the land area is classified as forest land (CARE, 2013).

The areas covered by this study include three communes, namely An Binh, An Thinh, and Dai Son in Van Yen district. The district's terrain is very diverse, with low valley locked between steep mountains. These three communes were selected since they are particularly characterized by (1) geographical zones; (2) flash flood and landslide situations; (3) economic patterns; and (4) ethnic minority groups. Also, the selection of these sites was carried out with the supports from officials in different organizations, such as the Department of Irrigation and Flood Control, the Agricultural Department, and the Statistical Department in Vietnam, as well as local leaders in these communes.

In the selected areas (Table 1), An Binh commune is located in the Northeast of the district. This commune is home to 4142 residents belonging to 'Kinh' (the only one major ethnic group among 54 ethnic groups in Vietnam) and 'Dao' groups. An Binh was established in 1979 when the Government called on people to live and work in the 
Table 1

Key characteristics of study areas.

Source: Authors' field survey in 2016.

\begin{tabular}{llll}
\hline Category & An Binh & An Thinh & Dai Son \\
\hline Total area $\left(\mathrm{km}^{2}\right)$ & 36.14 & 26.37 & 83.75 \\
Location & Middle land & Low land & Highland \\
Number of villages & 8 & 18 & 8 \\
Major Crops & Cassava & Rice & Cinnamon \\
Total population (persons) & 4142 & 9000 & 3249 \\
Population density (persons $\left./ \mathrm{km}^{2}\right)$ & 115 & 274 & 28 \\
Minority ethnic groups & Dao & Tay, Dao & Dao \\
\hline
\end{tabular}

commune (most of them were from Ha Nam (a delta province near Hanoi capital), and only a few were from Lao Cai - another mountainous province nearby). An Thinh is situated in the middle of the district. The commune has 9000 inhabitants, and most of them belong to 'Tay, Dao, and Kinh' groups. Most of the 'Kinh' people in An Thinh are Catholic. The commune was established in 1980, with 57 households moved from Thac Ba lake (another region in the province). The total population in Dai Son is 3249 people, and they belong to four main ethnic groups: 'Dao' (73,5\%), 'Tay, H'Mong, and Kinh'. Dai Son lies nearby An Thinh commune and has 2500 ha cinnamon. There is one cinnamon oil extracting company in Dai Son commune. All these three communes are classified as extremely disadvantaged and poor communes and supported by Program 135 from 2016 to 2020 (Pham et al., 2020).

The study used primary data collected from a household survey divided into two stages. In the first period between September and November 2015, we conducted in-depth interviews and focus group discussions in order to figure out the study background and also to determine the specific research areas in Van Yen district. In-depth interviews were undertaken with officials of the Agriculture Department, Departments of Irrigation and Flood Control, Meteorological Center, Statistical Departments in Yen Bai province, and chairmen in surveyed communes. The main focus covered in in-depth interviews were (1) livelihood activities, (2) weather conditions, (3) the situation of flash floods and landslides in recent 15 years, (4) main causes resulting in the occurrence of these natural disasters, and (5) which regions and who are strongly exposed to these natural hazards. In addition, three FGDs were uptaken with local farmers who are in different ranges of age and gender. Each FGD required the participant of a commune's official (a vice chairman of the commune or staff of the local agriculture department) since their presence helps people to be more open-mind in providing/sharing information, as well as to assist interviewers to verify the provided information. These FGDs contain information about agriculture-related production activities of farmers. Such information includes (i) crop calendar, (ii) challenges of farming activities, (iii) impacts of weather/climate and other factors (e.g., market price and institutional changes) on households' livelihoods, (iv) timeline and magnitude/scale of historical natural hazards, (v) types of natural hazards that local people have been experienced, and (vi) what kinds of measures they have been applying.

Meanwhile, a pre-test of the questionnaire was implemented with five households in each commune. After the pilot survey had been carried out, the questionnaire was revised for the formal household survey in the next fieldwork taken place from February to April 2016. In the second phase of data collection, we interviewed a total of 405 households in the selected communes. The sample structure is presented in Table 2 . In addition, the respondents in each commune were selected randomly from the list of households whose livelihoods and production activities impacted by flash floods and landslides, which were reported by local officers. The study does not choose respondents based on the ratio of the total population since the whole region and communes include both groups of people who have experienced and not experienced flash floods and landslides. In other words, the selection of surveyed samples in this study was based on the real affected magnitude of households in the research areas. In contrast, people who did not
Table 2

List of selected villages and samples.

\begin{tabular}{llc}
\hline Commune & Village & Samples \\
\hline An Binh & Khe Trang & 50 \\
& Khe Ly & 40 \\
& Khe Rong & 29 \\
& Hoa Nam & 12 \\
& Cau Cao & 22 \\
& Total samples in An Binh & 153 \\
An Thinh & Goc Nu & 37 \\
& Khe Cat & 27 \\
& Lang Cau & 13 \\
& Cua Ngoi & 29 \\
& Total samples in An Thinh & 106 \\
Dai Son & Thon 1 & 45 \\
& Thon 2 & 31 \\
& Thon 3 & 34 \\
& Thon 4 & 36 \\
& Total samples in Dai Son & 146 \\
& Sum of the totals & 405 \\
\hline
\end{tabular}

experience flash floods and landslides would not indicate reasonably or correctly the awareness toward these natural hazards; hence, they are not entirely suitable to answer the research questions and help achieve the research objectives. The collected data encompassed a wide range of variables, including eight sections: (1) household profile and housing, (2) general information about plots and land use, (3) crop production of the household, (4) irrigation, (5) livestock and aquaculture, (6) market, extension, (7) assets/savings/loans/income, (8) the perception regarding the frequency and impacts of flash floods and landslides on agricultural production and their livelihoods, as well as information related to adaptation responses, and social capital (see Annex).

The data collected from 405 sample households were entered into a computer following the Excel format and encoded into numeric structures. The input data were then thoroughly examined several times to check whether the existence of erroneous values appeared due to data input mistakes by using the Data Analysis and Statistical Software (STATA) version 14. Descriptive statistics and regression analysis are also critical approaches in this research. The descriptive statistics, including mean, standard deviation, frequency, and percentage, were used to present an overview of field study findings in terms of households' characteristics, effects of flash floods and landslides on households' livelihoods, and farmers' perception to changes in the frequency and impacts of these natural hazards. The analysis was quantified by employing non-parametric tests, including Kruskal Wallis, Pearson's Chi-squared, and Fisher's Exact tests. Then, the regression analysis (Multinomial Logit regression) was applied to investigate the determinants of households' perception of flash floods and landslides.

\subsection{Empirical model}

In general, to analyze the perception of farmers on changes in climatic events, the descriptive method is often used. However, with the goal is to pinpoint the factors determining the perception of farmers; different methods were used in the literature. For example, Tran et al. (2015) identified the awareness of small-scale farmers subject to climate change and variability in Vietnam by separating them into two groups: Poor and non-poor farmers; then listed the percentage of farmers for each change in climatic indicators based on the following four categories: 'increased', 'decreased', 'no change', and 'do not know'. The farmers' perceptions were tested by using the Chi-square index to see whether observations between poor and non-poor farmers are statistically significant and are in line with historical climatic data. This method is relatively simple because it does not explicitly indicate the factors affecting small-scale farmers' perceptions. By classifying farmers based on their farming experience, Maddison (2006) used years of farming experience as a criterion to find out how farmers perceived 
changes in climate, such as temperature, precipitation, and drought. Afterward, Maddison applied a probit regression method to examine whether the farmers' perception is sensitive to other factors mostly related to their socio-economic characteristics. The probit or logit regression method was also applied in other studies (Amadou et al., 2015; Gbetibouo, 2009). This method, on the other hand, is limited once the perception of respondents is not a binary outcome. In such a situation, the Multinomial Logit (MNL) model, an extension of logistic regression, is more advanced as it is able to explore potential relationships between the different levels of farmers' perception and a set of household attributes (Debela et al., 2015). Consequently, the MNL model is used to analyze the determinants of farmers' perception to flash floods and landslides in the research areas. This model is among the most frequently used nominal regression models and has been applied in a number of studies to identify factors affecting farmers' perception of climate change (Debela et al., 2015; Rosaine, 2014). The MNL model considers the relationship between a nominal dependent variable and a set of independent variables that either binary or continuous variables.

To describe the MNL model, let $P$ denote a random variable or a multinomial observation taking the values $\{1,2, \ldots, i(i=405)\}$ for I (a positive integer) and let $x$ denote a set of explanatory variables. In this case, $P$ denotes the perception options of farmers, $m$ stands for four categories: 'increased', 'decreased', 'no change', and 'do not know', and $x$ includes different households' attributes. The MNL model can be written as:

$$
\operatorname{Pr}_{\left(P_{i}=m \mid x_{i}\right)}=\frac{\exp \left(\mathrm{x}_{i} \beta m \mid b\right)}{\sum_{l=1}^{i} \exp \left(x_{i} \beta i \mid b\right)}
$$

where $b$ is a base case, which is also referred to as the comparison group. Suppose that we have four outcomes and fix the model with the alternative fourth as the base category, then Eq. (1) can be written as:

$\operatorname{Pr}_{\left(P_{i}=m \mid x_{i}\right)}=\frac{\exp \left(x_{i} \beta m \mid 4\right)}{\sum_{I=1}^{i} \exp \left(x_{i} \beta i \mid 4\right)}$

In the MNL model, under which the latent variables depend on covariate values that change across individuals but not across alternatives, an assumption of independent and identically distributed alternatives known as the Independence of Irrelevant Alternatives (IIA) are required (Young et al., 2009). More specifically, it denotes that the probability of perceiving a specific change on flash floods and landslides by a given respondent needs to be independent from the probability of perceiving other changes during these events. From the estimated parameters of the MNL model, the relative higher or lower probabilities compared to the base case are computed by using the exponential function. The following marginal effects are also derived from the MNL estimates to interpret the effects of independent variables on the probabilities (Wooldridge, 2010).

$$
\frac{\partial \mathrm{P}_{\mathrm{i}}}{\partial \mathrm{x}_{\mathrm{k}}}=\mathrm{P}_{\mathrm{i}}\left(\beta_{\mathrm{ik}}=\sum_{\mathrm{i}=1}^{\mathrm{i}-1} \mathrm{P}_{\mathrm{i}} \beta_{\mathrm{ik}}\right)
$$

The dependent variable $(\mathrm{P})$ in this research includes four categories of farmers' perception of flash floods and landslides. That is, they perceive that the frequency and impact of flash floods and landslides in the past 15 years (from 2000 to 2015) (1) 'did not change', (2) 'increased', (3) 'decreased' and (4) 'do not know' about it. The explanatory variables $(\mathrm{k}=1,2, \ldots, 12)$ include a set of twelve farmers' socioeconomic characteristics as described in Section 2.1. It is supposed that the perception model is a function of possible independent variables: (i) the agricultural experience of household head, (ii) male (gender), (iii) ethnic minority group (ethnicity), (iv) levels of education, (v) contact with extension services, (vi) farm size, (vii) distance to market, (viii) farm income, (ix) non-farm income, (x) poor household group (household status), (xi) climate information, and (xii) agro-ecological zone. Then, the perception model can be written as:

$P_{i}=\alpha_{0}+\sum \beta_{j} x_{i j}+u_{i}$

where:

$i$ stands for surveyed households ( $i=1,2,3, \ldots, 405)$;

$\alpha_{0}$ stands for the constant term or intercept;

$\beta_{j}$ is the parameters to be estimated;

$x_{i j}$ stands for $\mathrm{j}$ farmers' socio-economic characteristics; and.

$u_{i}$ is the error terms.

The MNL uses the method of Simulated Maximum Likelihood (SML) to estimate the contribution of explanatory variables to farmers' perception in each category: 'did not change', 'increased', 'decreased' and 'do not know'. The last category 'do not know' was used as the base case. Furthermore, since the estimated coefficients of the MNL model offer only the direction of the effect of the explanatory variables on the dependent variable, the marginal effects (MEs) of the MNL were also reported to know how the response variable affected by a unit change in an independent variable. The model was run by using STATA version 14 (statistical software).

\subsection{Choice of explanatory variables and hypotheses to be tested}

To explore factors influencing farmers' cognition to changes in frequency and impacts of flash floods and landslides, this study assumes that the perception process is affected by different exogenous variables listed in Table 3. These variables are divided into internal factors (i.e., gender, experience of household head in agriculture, ethnicity, education level, household condition, farm size, farm and non-farm income) and external factors (i.e., contact with extension services, distance to market, climate information, agro-ecological zone), which are specified based on the review of the literature (for example, see Semenza et al., 2008; Deressa et al., 2009; Gbetibouo, 2009; Below et al., 2011; Roco et al., 2014; Debela et al., 2015, Waibel et al., 2018; Zamasiya et al., 2017; Hasan and Kumar, 2019), expert interviews, and own observations during the field study.

(1) Internal factors:

- Gender (male is defined as a subject ' $=1$ '): With evidence from Uganda, Ghana, and Bangladesh, it is indicated by Jost et al. (2015) that men appear to be more dominant in receiving information on weather alerts and extension services. In general, rural women in mountainous regions are often responsible for childcare, collection of firewood and water - these tasks were described as light works - considered to be the main reason leading women to have less access to climate information. Accordingly, it is expected that women are less likely to perceive changes in the frequency and impacts of past flash floods and landslides. Often, they may think the impacts are just similar to the impacts of heavy rains without thinking of more serious events like flash floods and landslides.

- Agricultural experience: Experience in agriculture is determined by the time period (measured in years) that the households' heads have been working in their agricultural farms. Such experience becomes important, as they would be familiar with the environment and changes in the working conditions over time that may help farmers predict changes in climate events. It is also evident from the works conducted by Hansen et al. (2004), Gbetibouo (2009), and Silvestri et al. (2012) that farmers with more experience are more likely to perceive temperature changes. Hence, the study hypothesizes that the higher experience of farmers, the higher perception of the frequency and impacts of flash floods and landslides they experience. 
Table 3

Predictor variables of the perception model.

\begin{tabular}{|c|c|c|c|}
\hline Variables & Type & Modalities & Expected sign \\
\hline \multicolumn{4}{|l|}{ Internal factors } \\
\hline Experience in agriculture (years) & $\mathrm{C}$ & None & + \\
\hline Male (gender) & $\mathrm{D}$ & $1=$ male; $0=$ female & + \\
\hline Ethnic minority group (ethnicity) & $\mathrm{D}$ & $1=$ Ethnic minority groups; $0=$ 'Kinh' majority group & + \\
\hline Level of education (degree) & $\mathrm{C}$ & 1: Illiteracy; 2: primary school; 3 : secondary school; 4 : high school and higher & + \\
\hline Poor household (household condition) & $\mathrm{D}$ & $1=$ poor household; $0=$ non-poor household & + \\
\hline Farm size (ha) & $\mathrm{C}$ & None & + \\
\hline Farm income (million VND) & $\mathrm{C}$ & None & + \\
\hline Non-farm income (million VND) & $\mathrm{C}$ & None & + \\
\hline \multicolumn{4}{|l|}{ External factors } \\
\hline Contact with extension services & $\mathrm{D}$ & $0=$ no; $1=$ yes & + \\
\hline Distance to market $(\mathrm{km})$ & $\mathrm{C}$ & None & - \\
\hline Information on climate & $\mathrm{D}$ & $0=$ no; $1=$ yes & + \\
\hline \multicolumn{4}{|l|}{ Agro-ecological zone } \\
\hline An Binh & $\mathrm{D}$ & $1=$ the farm in An Binh and $0=$ otherwise & \pm \\
\hline An Thinh & $\mathrm{D}$ & $1=$ the farm in An Thinh and $0=$ otherwise & \pm \\
\hline Dai Son & $\mathrm{D}$ & $1=$ the farm in Dai Son and $0=$ otherwise & \pm \\
\hline
\end{tabular}

Note: D: discontinuous variables; C: continuous variables.

- Ethnicity (ethnic minority group is selected as a subject ' $=1$ '): As pointed out by Pham et al. (2010) and Pham et al. (2019), these minority groups often live in remote areas and villages less endowed with infrastructure. Besides, their livelihood activities are greatly dependent on agriculture, which is often heavily affected by flash floods and landslides. These people may, therefore, highly pay attention to the changes of these natural disasters. Hence, this study hypothesizes that if the head of the household belongs to any ethnic minority group, it will be likely to increase the probability of perceiving changes in the frequency and impacts of flash floods and landslides.

- The education level of the household head: Educated farmers would have more capacity to access and understand disseminated information (Marx et al., 2007; Weber, 2010). It is often observed that educated farmers are more likely to notice changes in climate (Gbetibouo, 2009; Huda, 2013). The research, hence, assumes that a higher level of education will positively correlate with perceiving changes in the frequency and impacts of flash floods and landslides.

- Household condition (poor household is defined as a subject '= 1'): This variable identifies household income characteristics: poor and non-poor households, as classified by the Ministry of Labor and Social Affairs of Vietnam. Since the research sites in this study are rural areas, a poor rural household is defined with a monthly income equal to or below 700,000 VND (around $\$ 30$ ). It is often observed in the study regions that while wealthier farmers often reside in favorable locations, poor households typically live in remote areas where flash floods and landslides occur frequently. This may lead to the possibility that the poor will be more interested in updating the changes of these natural disasters than the non-poor. Likewise, the present research hypothesizes that there is a positive relationship between poor household and farmers' cognition about the variations of flash floods and landslides.

- Farm size: A farmer with a large scale farm usually needs to invest more inputs in agricultural production, leading to higher opportunity costs. Hence, they would pay more attention to climate matters, such as rainfall, temperature, flood, drought, etc. It is subsequently assumed in this study that farm size would be positively associated with the perception of farmers toward changes in the frequency and impacts of flash floods and landslides that happened in the region.

- Farm and non-farm income: The influence of farm and non-farm income on the farmers' awareness on this matter is assumed to be different. Households with more farm activities are hypothesized to be more aware of changes in the frequency and impacts of flash floods and landslides since their livelihoods greatly rely on agriculture. While households with the main income from non-farm activities might not highly pay their attention to climate factors. Thus, farmers with higher farm income are expected to be more likely to perceive changes in the frequency and impacts of flash floods and landslides; meanwhile, an opposite trend is assumed in the case of non-farm income.

\section{(2) External factors}

- Availability of extension services ${ }^{2}$ : With the aim of promoting agricultural productivity, increasing food security, and improving rural livelihoods, agricultural extension services facilitate farmers' access to knowledge, information, and technologies. Thus, this research hypothesizes that contact with extension services increases the likelihood of perceiving changes in the frequency and impacts of flash floods and landslides.

- Distance to market: Maddison (2006) identified that the market serves as a resource of interchanging information with other farmers. The negative relationship between distance to market and perception of flash floods and landslides is thus hypothesized.

- Climate information: According to Deressa et al. (2009), Maddison (2006), and Nhemachena and Hassan (2008), precise information on climate may help people to uptake the right decision to adapt to changes in climate. It is therefore assumed that access to information on weather and climate will increase the likelihood of observing changes in the events of flash floods and landslides.

- Agro-ecological zone: The characteristics of agro-ecological zones would be significantly different from one to the others. We thus hypothesized that the agro-ecological zone would have a mixed effect on the farmer's awareness of changes in the frequency and impacts of flash floods and landslides.

\section{Results and discussions}

\subsection{Farmers' characteristics}

The socio-economic characteristics of surveyed respondents are shown in Table 4. Our household survey results indicated that, on average, the household heads have 26.77 ( \pm 11.93 ) years of experience in agriculture, which is determined by the period that a household head started

\footnotetext{
2 There are some services provided by extension officials (called extension services), such as transferring information and knowledge in organizing and managing agricultural production (seedling, breeding, preventing pests, updating market price and so on), as well as training farmers with new varieties.
} 
Table 4

The details of the explanatory variables used in the perception model.

\begin{tabular}{llrrlr}
\hline Variables & Type & Mean & Std.D & Min & Max \\
\hline Internal factors & & & & & \\
Experience in agriculture (years) & $\mathrm{C}$ & 26.77 & 11.93 & 1 & 66 \\
Male (gender) & $\mathrm{D}$ & 0.90 & 0.30 & 0 & 1 \\
Ethnic minority group (ethnicity) & $\mathrm{D}$ & 1.75 & 0.64 & 1 & 3 \\
Poor household (household condition) & $\mathrm{D}$ & 116 & 28.64 & 0 & 1 \\
Level of education (degree) & $\mathrm{C}$ & 1.83 & 1.33 & 0 & 8 \\
Farm size (ha) & $\mathrm{C}$ & 2.32 & 2.52 & 0.012 & 25.21 \\
Farm income (million VND) & $\mathrm{C}$ & 55.99 & 80.55 & 0 & \\
Non-farm income (million VND) & $\mathrm{C}$ & 35.06 & 42.62 & 0 & \\
External factors & & & & & \\
Contact with extension services (0/1) & $\mathrm{D}$ & 0.24 & 0.43 & 0 & 1 \\
Distance to market (km) & $\mathrm{C}$ & 3.74 & 2.68 & 0.1 & 35 \\
Information on climate (0/1) & $\mathrm{D}$ & 0.91 & 0.29 & 0 & 1 \\
\hline
\end{tabular}

working in agricultural fields. In addition, most of the interviewed households are headed by men (about $90 \%$ of the total respondents), and $65 \%$ of them belong to ethnic minority groups, for example, 'Dao' (Black Dao and White Dao), 'Tay', and 'Hoa'. Approximately $29 \%$ of surveyed households are documented in the poor household list. Generally, the education levels of the respondents are low in the research area. Remarkably, there are approximately $42 \%$ of illiterate household heads in the whole sample. The average landholding size is 62.35 'Sao'3 (equivalent to $2.32 \mathrm{ha}$ ) per household. Besides, family income includes farm and nonfarm income, of which farm income was the primary earning source of most surveyed farmers.

The connection between farmers and extension staffs in the research area has not been really focused, indicating by rare visits of the extension officials to households in the last 12 months. Only about $24 \%$ of the respondents reported the visits of officials. In addition, the average distance to the closest commune market was $3.73 \mathrm{~km}$.

\subsection{Effects of flash floods and landslides on the livelihood of farmers in the research areas}

The severity of natural hazards often results in complex and substantial impacts on the agricultural sectors, especially on marginalized rural population groups (Funk et al., 2020; Singh et al., 2020). Interviewed farmers were asked In which aspects and to what extend your family's livelihoods have been affected by flash floods and landslides. With respect to this issue, a number of interviewees, accounting for $95 \%$ of the surveyed farmers, disclosed their rigorous experience in adverse impacts of flash floods and landslides over the past 15 years (Table 5). In particular, it is reported by $93 \%$ of all respondents that one of the most observed impacts of these climate-induced hazards is admitted as a critical reason for crop failure and reductions in productivity, which in the long run could lead to food insecurity. Local farmers, in addition, have pointed out the uncertainty in their incomes as an inevitable consequence of such hazards due to reduced output levels, owning by heavy dependence of their incomes on agriculture. Subsequently, there are a majority of surveyed households (97\%) claimed decreases in their household incomes in recent years. It is due to the fact that farm income has a major share of the total family income compared to non-farm incomes.

In addition, the local community also declared that they are confronting more obstructive and challenging working conditions (87\%) under intensive pressures of flash floods and landslides. For example, since landslides often cause fields to be buried by rocks and soils, and people could not afford to hire machines due to budget constraints, they had to carry out/clear rocks and stones all by themselves. As such, more labor is required for farming activities than

\footnotetext{
${ }^{3}$ A measurement of agricultural land in Vietnam.
}

Table 5

Effects of flash floods and landslides on farmers in the research areas.

Source: Authors' field survey in 2016.

\begin{tabular}{lccrrr}
\hline & An & An & \multicolumn{1}{l}{ Dai } & Average & $P$-value \\
& Binh & \multicolumn{1}{c}{ Thinh } & \multicolumn{1}{l}{ Son } & & \\
\hline No effect & $1.3 \%$ & $2.86 \%$ & $9.59 \%$ & $4.69 \%$ & 0.002 \\
Reduce productivity & $96.1 \%$ & $97.09 \%$ & $86.30 \%$ & $92.80 \%$ & 0.001 \\
Lost livestock, aquaculture & $33.77 \%$ & $27.88 \%$ & $21.23 \%$ & $27.72 \%$ & 0.053 \\
Cause diseases in people & $37.66 \%$ & $56.73 \%$ & $27.40 \%$ & $38.86 \%$ & 0.000 \\
Cause diseases in livestock, poultry & $50.65 \%$ & $74.04 \%$ & $23.97 \%$ & $47.03 \%$ & 0.000 \\
Lost land & $31.82 \%$ & $18.27 \%$ & $43.84 \%$ & $32.67 \%$ & 0.000 \\
Reduce income & $94.81 \%$ & $99.04 \%$ & $96.58 \%$ & $96.53 \%$ & 0.210 \\
Cause injury, death & $2.6 \%$ & $2.88 \%$ & $1.37 \%$ & $2.23 \%$ & 0.758 \\
Damage housing, assets & $35.71 \%$ & $38.46 \%$ & $21.23 \%$ & $31.19 \%$ & 0.005 \\
Increase daily expenses & $42.21 \%$ & $53.85 \%$ & $95.21 \%$ & $64.36 \%$ & 0.000 \\
More hardly working conditions & $82.47 \%$ & $79.81 \%$ & $97.95 \%$ & $87.38 \%$ & 0.000 \\
\hline
\end{tabular}

$P$-values are provided according to Pearson's chi-squared and Fisher's exact tests.

usual. It was recounted by Mr. Truong Van Minh, residing in Khe Khe group - Khe Trang village, An Binh commune, that cinnamon and cassava were grown on 3 ha hilly land inherited from his parents. However, a catastrophic landslide in 1998 compelled pronounced damages to his cultivated land. The whole cinnamon trees were devastated, leading to a loss of approximately 90 million VND (about US \$3900). In addition, around 0.5 ha of cultivated land has been inoperative afterwards.

The surveyed results also reveal miscellaneous uncertainties translated by flash floods and landslides, such as increased daily expenses (informed by $64 \%$ of respondents), causing diseases in livestock and poultry (47\%), people (39\%), and losing land (33\%). On average, there are approximately $5 \%$ of total respondent households stating that they were not affected by the negative impacts of flash floods and landslides, in which most of them were living in Dai Son commune. Respondent households in the research areas commonly noted that flash floods and landslides have severe effects on the scale of productive land (stated by $32 \%$ of interviewees), that is already restricted due to the steep terrain and inhabitants' pressures since many fields or forest areas had been uncultivated due to buried rocks and soil. Flash floods and landslides are estimated to normally cause damages to infrastructure and limit access to the market. Also, due to these natural hazards, mud, stones, and rocks are often accumulated in the fields that generate even worse and long-term damage than single disasters, such as floods and drought. In this situation, farmers need to invest more labor forces to recover their agricultural land. In many cases, land is no longer suitable for future cultivation. Another story was shared by a household headed woman, Mrs. Ly Thi Lin in 'Five' group - Khe Rong village, An Binh commune, that in 2008 her house was swept away due to one of the most striking flash floods she had been witnessed in 40 years in the commune. Due to the event, her house was totally destructed, and all crops in two 'Sao' (approximately $0.072 \mathrm{ha}$ ) of agricultural land were wiped, costing equivalent to around 100 million VND (approximately US\$4350). Her family was then moved to the current house according to the commune's support policy.

\subsection{Farmer's perception of flash floods and landslides}

Farmers were asked to give their observations regarding changes in the frequency and impacts of flash floods and landslides based on their experiences over the past 15 years in their living areas during the focus group discussions and household surveys. Then, farmers' perceptions of flash floods and landslides in terms of the frequent changes consist of four categories (Table 6). That is, they perceive that the frequency and impacts of flash floods and landslides over the past 15 years (from 2000 to 2015) (1) 'did not change', (2) 'increased', (3) 'decreased' and (4) 'do not know'. Almost all respondents perceive changes in the frequency and impacts of flash floods (97\%) and landslides (93\%). It is noticeable that the annual occurrence of flash floods and landslides has 
Table 6

Farmer's perception of flash floods and landslides.

Source: Authors' field survey in 2016.

\begin{tabular}{llrrrrr}
\hline & An Binh & An Thinh & Dai Son & Average & $P$-value \\
\hline \multirow{2}{*}{ Flash flood } & Did not change & $22.08 \%$ & $19.05 \%$ & $8.22 \%$ & $16.30 \%$ & 0.0001 \\
& Increased & $25.97 \%$ & $30.48 \%$ & $85.62 \%$ & $48.64 \%$ & \\
& Decreased & $46.10 \%$ & $49.52 \%$ & $5.48 \%$ & $32.35 \%$ & \\
& Do not know & $5.84 \%$ & $0.99 \%$ & $0.68 \%$ & $2.72 \%$ & \\
Landslide & Did not change & $23.38 \%$ & $27.62 \%$ & $10.96 \%$ & $20 \%$ & 0.0001 \\
& Increased & $27.27 \%$ & $13.33 \%$ & $77.40 \%$ & $41.73 \%$ & \\
& Decreased & $40.26 \%$ & $48.57 \%$ & $10.27 \%$ & $31.60 \%$ & \\
& Do not know & $9.09 \%$ & $10.48 \%$ & $1.37 \%$ & $6.67 \%$ & \\
\hline
\end{tabular}

$P$-value is provided according to Kruskal-Wallis test.

been estimated to increase in the past 15 years (from 2000 to 2015) by most of the respondents on average. It is also denoted that local individuals are facing difficulties in predicting/estimating flash floods and landslides due to unstable and abnormal alterations over the past years. For example, in the past, flash floods often occurred from May to August, yet, in recent years, the local community might witness such event in October or in February, as mentioned by Mr. Lich in An Thinh commune. Although changes of these climate-induced hazards have been aware of throughout the research areas, the farmers' perception of each of these events is profoundly different between Dai Son and the other two communes. While most of the respondents in Dai Son perceived an increased trend of flash floods and landslides ( $85.62 \%$ and $77.40 \%$, correspondingly), a majority of farmers in An Binh and An Thinh communes observed the decreased trend of these weather events (ranges from roughly $40 \%$ to $50 \%$ ). In addition, farmers in Dai Son commune are seen to be more likely to be aware of the changes in flash flood and landslide events. The likely reason might be that Dai Son's community has been exposed and hit more frequently by flash floods and landslides; hence, local people may be more noticed to such events. Also, livelihood activities of respondents in Dai Son have significantly relied on agriculture that is strongly influenced by weather factors and conditions, so they might pay more attention to changes in these natural hazards in order to minimize the negative impacts of flash floods and landslides. About $16 \%$ and $20 \%$ of total respondent households noticed that there had been no change in the annual frequency and impacts of flash floods and landslides over the last 15 years. They perceive that they have been affected the same over the years in terms of both health conditions as well as physical damages (such as crop failure, damaged houses, and destroyed cultivation fields), and the frequency of such hazards is similar over time. Statistical results, according to the Kruskal-Wallis test, show that perceiving changes in the frequency and impacts of flash floods and landslides is significantly different among the three communes $(P<0.01)$.

\subsection{Factors determining the local community's attitudes: results from the Multinomial Logit regressions}

The influences of each households' socio-economic variable on how farmers' awareness of changes in flash floods and landslides are presented in Tables 7 and 8, derived from Multinomial Logit regressions. The models were tested for multicollinearity by using the variance inflation factor (VIF). In addition, the validity of the independence of the irrelevant alternatives (IIA) assumptions was examined for both the models by using both the Hausman tests and the Small - Hsiao tests. Model test results are provided in Appendix A, which indicate that the Multinomial Logit models are significant $(P<0.01)$ and relevant in detecting the farmers' perspectives. The estimated correlations from Tables 7 and 8 allow us to understand whether predictor factors have a positive or inverse connection with people's attitudes. Besides, marginal effects are also applied in order to further inspect the variation in the probability of a particular choice in the perception of changes in the frequency and impacts of flash floods subject to a unit change in the independent variables. Results of the marginal effects are presented in Tables B1 and B2 in Appendix B.

Among the 12 independent variables categorizing as internal and external factors hypothesized in the perception models, seven variables were found as significant predictors (at different levels including $P<0.1, P<0.05$, and $P<0.01$ ) influencing the ways local people noticed changes of flash floods and landslides. These significant explanatory elements consist of (1) agricultural experience, (2) male (gender), (3) ethnic minority group (ethnicity), (4) poor household (household

Table 7

Determinants of MNL model for farmers' perception of flash floods (estimated coefficients and relative risk ratios (RRR)).

Source: Authors' own estimation.

\begin{tabular}{|c|c|c|c|c|c|c|}
\hline \multirow[t]{3}{*}{ Variables } & \multicolumn{6}{|l|}{ Perception } \\
\hline & \multicolumn{2}{|l|}{ Did not change } & \multicolumn{2}{|l|}{ Increased } & \multicolumn{2}{|l|}{ Decreased } \\
\hline & Coefficient (RRR) & $P>|z|$ & Coefficient (RRR) & $P>|z|$ & Coefficient (RRR) & $P>|z|$ \\
\hline \multicolumn{7}{|l|}{ Internal factors } \\
\hline Experience in agriculture & $0.079(1.082)^{*}$ & 0.056 & $0.077(1.080)^{*}$ & 0.062 & $0.102(1.107)^{* *}$ & 0.013 \\
\hline Male (gender) & $1.701(5.479)^{*}$ & 0.079 & $1.224(3.401)$ & 0.190 & $1.684(5.387)^{*}$ & 0.075 \\
\hline Ethnic minority group (ethnicity) & $2.290(9.875)$ & 0.107 & $2.705(14.954)^{*}$ & 0.056 & $2.435(11.416)^{*}$ & 0.085 \\
\hline Poor household (household condition) & $0.124(1.132)$ & 0.890 & $-0.327(0.721)$ & 0.715 & $-0.246(0.782)$ & 0.784 \\
\hline Education level & $-0.071(0.931)$ & 0.859 & $-0.193(0.824)$ & 0.623 & $-0.092(0.912)$ & 0.818 \\
\hline Farm size in ha & $0.373(1.452)$ & 0.351 & $0.381(1.464)$ & 0.337 & $0.495(1.640)$ & 0.213 \\
\hline Farm income & $0.018(1.018)$ & 0.476 & $0.021(1.021)$ & 0.402 & $0.020(1.020)$ & 0.421 \\
\hline Non-farm income & $-0.014(0.986)$ & 0.142 & $-0.015(0.985)$ & 0.118 & $-0.014(0.986)$ & 0.147 \\
\hline \multicolumn{7}{|l|}{ External factors } \\
\hline Contact extension services & $0.627(1.872)$ & 0.487 & $0.766(2.151)$ & 0.393 & $0.292(1.339)$ & 0.746 \\
\hline Distance to market & $-0.159(0.853)^{*}$ & 0.098 & $-0.179(0.836)^{*}$ & 0.071 & $-0.142(0.868)$ & 0.138 \\
\hline Climate information & $0.714(2.042)$ & 0.416 & $1.506(4.509)^{*}$ & 0.090 & $2.181(8.855)^{* *}$ & 0.023 \\
\hline An Thinh & $1.321(3.747)$ & 0.299 & $1.578(4.845)$ & 0.213 & $1.382(3.983)$ & 0.273 \\
\hline Dai Son & $1.622(5.063)$ & 0.245 & $4.173(64.909)^{* * * *}$ & 0.002 & $0.367(1.443)$ & 0.797 \\
\hline Constant & $-2.491(0.082)$ & 0.188 & $-2.540(0.079)$ & 0.172 & $-3.976(0.019)^{* *}$ & 0.041 \\
\hline
\end{tabular}

Note: The base case: 'do not know' whether there were changes in the frequency and impacts of flash floods.

Numbers in parentheses are risk relative ratios, which are in the exponential form of the values outside the parentheses.

LR chi-square $(39)=202.06$ Prob $>$ chi-square $=0.0000$.

Log likelihood $=-347.794$ Pseudo $\mathrm{R}^{2}=0.2251$.

* Significant at $10 \%$.

** Significant at $5 \%$.

*** Significant at $1 \%$. 
Table 8

Determinants of MNL model for farmers' perception of landslides (estimated coefficients and relative risk ratios (RRR)).

Source: Authors' own estimation.

\begin{tabular}{|c|c|c|c|c|c|c|}
\hline \multirow[t]{3}{*}{ Variables } & \multicolumn{6}{|l|}{ Perception } \\
\hline & \multicolumn{2}{|l|}{ Did not change } & \multicolumn{2}{|l|}{ Increased } & \multicolumn{2}{|l|}{ Decreased } \\
\hline & Coefficient (RRR) & $P>|z|$ & Coefficient (RRR) & $P>|z|$ & Coefficient (RRR) & $P>|z|$ \\
\hline \multicolumn{7}{|l|}{ Internal factors } \\
\hline Experience in agriculture & $0.018(1.018)$ & 0.423 & $0.014(1.014)$ & 0.524 & $0.039(1.040)^{*}$ & 0.073 \\
\hline Male (gender) & $2.000(7.389)^{* *}$ & 0.016 & $0.428(1.534)$ & 0.547 & $1.187(3.277)$ & 0.103 \\
\hline Ethnic minority group (ethnicity) & $1.389(4.011)^{* *}$ & 0.033 & $2.010(7.463)^{* * * *}$ & 0.003 & $1.910(6.753)^{* * *}$ & 0.003 \\
\hline Poor household (household condition) & $1.403(4.067)^{* *}$ & 0.037 & $0.734(2.083)$ & 0.273 & $0.800(2.226)$ & 0.236 \\
\hline Education level & $0.249(1.283)$ & 0.279 & $-0.022(0.978)$ & 0.922 & $0.025(1.025)$ & 0.912 \\
\hline Farm size in ha & $-0.105(0.900)$ & 0.372 & $-0.128(0.879)$ & 0.192 & $-0.053(0.948)$ & 0.590 \\
\hline Farm income & $-0.003(0.997)$ & 0.485 & $0.002(1.002)$ & 0.595 & $0.001(1.001)$ & 0.798 \\
\hline Non-farm income & $-0.007(0.993)$ & 0.259 & $-0.007(0.993)$ & 0.258 & $-0.002(0.998)$ & 0.747 \\
\hline \multicolumn{7}{|l|}{ External factors } \\
\hline Contact extension services & $0.369(1.446)$ & 0.500 & $0.316(1.372)$ & 0.562 & $-0.240(0.787)$ & 0.658 \\
\hline Distance to market & $-0.036(0.965)$ & 0.665 & $0.023(1.023)$ & 0.771 & $0.063(1.065)$ & 0.413 \\
\hline Climate information & $0.685(1.986)$ & 0.311 & $1.967(7.149)^{* * *}$ & 0.006 & $3.545(34.640)^{* * *}$ & 0.000 \\
\hline An Thinh & $-0.442(0.643)$ & 0.439 & $-1.380(0.252)^{* *}$ & 0.020 & $-0.733(0.480)$ & 0.179 \\
\hline Dai Son & $1.126(3.083)$ & 0.245 & $3.761(42.991)^{* * * *}$ & 0.000 & $0.995(2.705)$ & 0.304 \\
\hline Constant & $-2.181(0.113)$ & 0.119 & $-1.778(0.169)$ & 0.184 & $-4.493(0.011)^{* * *}$ & 0.005 \\
\hline
\end{tabular}

Note: The base case: 'do not know' whether there were changes in the frequency and impact of landslides.

Numbers in parentheses are risk relative ratios, which are in the exponential form of the values outside the parentheses.

LR chi-square $(39)=207.90$ Prob $>$ chi-square $=0.0000$.

Log likelihood $=-392.81622$ Pseudo $\mathrm{R}^{2}=0.2093$.

* Significant at $10 \%$

** Significant at $5 \%$.

**** Significant at $1 \%$.

condition), (5) distance to market, (6) information on climate, and (7) agri-ecological zone. On the other hand, the empirical results also specified that education level, farm size, farm income, non-farm income, and contact to extension services are statistically non-significant $(>10 \%$ confidence level) to farmers' cognitive to these climate-induced hazards in the surveyed regions. Detailed explanations of the regression's results are discussed below.

\subsubsection{Internal factors}

3.4.1.1. Experience in agriculture. Experience in agriculture may be considered as a proxy of farmers' age. In both models, the agricultural experience is positively related to all farmers' attitudes to changes in the frequency and impacts of flash floods and landslides. The regression results show statistically significant associations between experience in agriculture and people's perception of flash flood events in all cases $(P<0.05$ and $P<0.1)$ (Table 7$)$; and only in the case local farmers perceived landslide events 'decreased' $(P<0.1)$ (Table 8$)$. Hence, it indicates that more experience in agriculture of the household head would bring them a higher probability not only in recognizing changes in the frequency and impacts of flash floods but also in noticing a decreasing trend of landslides. In addition, risk relative ratios' results (Table 7) show that one more year working in agriculture would lead to a higher probability of perceiving the 'did not change', 'increased', and 'decreased' in the frequency and impacts of flash flood events relative to the 'do not know' option by $8.20 \%, 8.00 \%$, and $10.7 \%$, correspondingly. Besides, a one-year increase in the farming experience is associated with a higher probability of $4.0 \%$ in observing the 'decreased' in the frequency and impacts of landslides compared to the "do not know option' (Table 8). The research findings are in line with the statements given by Cullen and Anderson (2016) and Liverpool-Tasie et al. (2020), who concluded that rural farmers' observation might be shaped by well-being experiences in livelihood activities of the households. It is further noted that senior farmers, who had a long time devoted to practices in agriculture, would have more knowledge related to climate-induced disasters, leading to their cognitive acumen (Ahmad and Afzal, 2020; Ayal and Leal Filho, 2017; Funatsu et al., 2019; Khan et al., 2020).
3.4.1.2. Male (gender). As hypothesized, the coefficients of gender variable are positive, which depict that male-headed households had better awareness about changes in the frequency and impacts of flash floods and landslides. The estimated correlations disclose that being a male significantly increases the probability of farmers in perceiving 'did not change' and 'decreased' of flash floods at a $10 \%$ significance level, and in recognizing changes of landslide 'did not change' at a 5\% significance level. The relative risk ratios from both models display that the probability for male in perceiving the 'did not change' and 'decreased' in the frequency and impacts of flash floods relative to the 'do not know' option is about 4.5 times $(=5.479-1)$ and four times $(=5.387-1)$, respectively, higher than for female while it is six times $(=7.389-1)$ higher for a man than for a woman in the probability of perceiving the "did not change' option compared to the 'do not know' choice for landslide events. In addition, the values of marginal effects given in Table B2 (Appendix B) show a 16.1 percentage point higher in the probability of a man in noticing the 'did not change' option of landslides compared to a woman. The probable explanation might be that women in the surveyed areas usually take responsibility for children caring and household activities, thus causing them to have less access and connection to information and outside resources than men. Hence, they are not as sensitive as men in realizing changes in such climate-induced disasters. This result is also in accordance with empirical findings from Ahmad and Afzal (2020), Huda (2013), Sharma et al. (2020), and Tesfahunegn et al. (2016), who reported that male is more likely to perceive climate stimuli. Likewise, it might be concluded that gender is likely to determine local farmers' attitudes to flash floods and landslides.

3.4.1.3. Ethnic minority group (ethnicity). Ethnicity presented as a proxy for smallholder farmer's characteristics in remote and mountainous regions of Vietnam. The regression results disclose that the ethnic minority group has a significantly positive correlation with individuals' cognitive of changes in the frequency and impacts of flash floods and landslides. Results of risk relative ratios, besides, provide that the probability of the ethnic minority group in perceiving changes of these natural disasters is much higher than the 'Kinh' people. For example, it is 14 times higher in the probability of the ethnic minority group in noticing changes in flash floods and landslides compared to the 'Kinh' 
majority group. Marginal effect calculations further point out that being ethnic minority groups would result in a lower probability of 6.2 percentage points than the 'Kinh' people in not perceiving of landslides (Table B2 in Appendix B). This finding suggests that ethnic minority groups such as 'Tay', 'Dao' in the study communities tend to be not likely to misperceive changes of flash floods and landslides compared to the 'Kinh' people. It is derived from the fact that ethnic minority groups often live in upland and marginal areas making them become more exposed to the effects of flash floods and landslides. In addition, they often rely their livelihoods more on agricultural and forestry activities, which are climate-driven, than the 'Kinh' people; hence, people in these areas are more likely to observe and notice changes of these natural hazards.

3.4.1.4. Poor household (household condition). The poor household variable shows a mixed effect on farmers' perception to flash floods and landslides. It has exhibited a negative relation to the farmers' awareness of changes in the frequency and impacts of flash floods (except for the 'did not change' option); however, the coefficients are not significant. On the other hand, the estimated coefficients are positively correlated with the perception of landslides in all cases, yet only significant in perceiving the 'did not change' option at a 5\% significance level. It is further given additional information by the risk relative ratio calculation that a non-poor household might have a less three times $(=4.067-1)$ in the likelihood of perceiving 'did not change' relative to 'do not know' option in changes of landslides. Furthermore, results from the marginal effects suggest that being a poor household results in a higher probability of 12.2 percentage points in perceiving 'did not change' of landslides compared to the non-poor household (Table B2 in Appendix B). The result is also supported by a previous study (Ayal and Leal Filho, 2017), which concluded that poorer-farmer might be in a better position to have a sensation of climate variability. The positive and significant correlation can be explained by the fact that most poor households are located in Dai Son commune that is the most vulnerable area in the research site and is heavily affected by landslides (Pham et al., 2020). Furthermore, the local community excessively relies on agriculture, which is under increasing pressure led by negative impacts of landslides, as a primary source of income. Subsequently, we reach a conclusion that farmers who are the poor might be well aware of the effects as well as changes of landslides.

\subsubsection{External factors}

3.4.2.1. Distance to market. As expected, negative estimated coefficients are found between the distance to market variable with farmers' perception of flash floods and landslides in almost all categories (except for the cases of perceiving 'increased' and 'decreased' of landslides). The finding demonstrates that households with favorable distance to market are more likely to enhance the probability of noticing changes in flash floods and landslides. This is attributed by the fact that the market is considered to be a useful information channel for local farmers (Pham et al., 2019). However, the estimated correlation is statistically significant in only the case of perceiving 'did not change' $(P<0.1)$ and 'increased' $(P<0.1)$ for farmers' perception related to flash floods. The results of relative risk ratios imply that $1 \mathrm{~km}$ further in the distance to market will result in a lesser probability of perceiving the 'did not change' option and 'increased' option relative to the 'do not know' option for flash flood events by about $0.8 \%$. Indeed, a similar finding was documented with a case study in Bangladesh by Hasan and Kumar (2019), who denoted that the more the distance to market, the fewer farmers' perception of climate stimuli.

3.4.2.2. Climate information. Findings indicate that climate information has a positive relationship with the perception of flash floods and landslides in all categories, which indicates that receiving and keeping weather information updated could bring farmers a precise and sharper cognition regarding upcoming weather irregularities as well as flash floods and landslides. The regression estimates display that information on climate has a statistically significant positive association with farmers' perception in noticing changes of flash floods at a $10 \%$ significance level and of landslides at a 5\% significance level. Results of relative risk ratios further point out how different in noticing changes of such natural hazards if farmers are able to access climate information. For example, the probability of noticing the 'decreased' relative to the 'do not know' option in the frequency and impacts of flash floods is about eight times $(=8.855-1)$ higher for people who get climate information compared to those have no information. A similar statement was reported by Khan et al. (2020) and Roco et al. (2014). It is noted that local communities can access information on weather conditions through different types of social media such as radio, television, or via the village's meeting. It is plausible that available access to weather information might increase individuals' awareness since the more availability and timeliness of climate information, the more farmers' perception of such natural disasters.

3.4.2.3. Agro-ecological zone. The regression results, presented in Tables 7 and 8 with the estimated coefficient at $1 \%$ and 5\% significance levels, support the research hypothesis that household location is a pertinent predictor that needs to be investigated in order to comprehend how flash floods and landslides are recognized in the surveyed sites. The results are consistent with previous studies (Khan et al., 2020; Roco et al., 2014), which demonstrated that farmers' awareness often varies across different agro-ecological zones; the present study has shown that local differences have two directions (either positive or negative) significantly impacting people's perception. It is worthy noting that the agro-ecological zone has a positive relationship with farmers' perception of all categories in An Binh and An Thinh, while a negative sign is reported in Dai Son. However, the estimated correlation is positively significant in only the case of noticing 'increased' in the frequency and impacts of both flash floods and landslides in Dai Son commune $(P<0.01)$ and negatively significant in the case of noticing 'increased' in changes of landslides in An Thinh commune $(P<0.05)$. Such correlations reveal that farmers in An Thinh are less likely to perceive increased changes in landslides, while farmers from Dai Son are more likely to notice increased changes in both these natural hazards. These findings are derived from the fact that An Thinh is located in a flat terrain with more developed infrastructure, where people experience less occurrence of landslides than in the past; thus, the community in these areas might have less notice of an increasing trend in landslides. On the other hand, smallholder farmers in Dai Son (the most hilly and remote area with poor road and facility quality among three researched communes) had been more exposed and undergone impressive influences of flash floods and landslides. Consequently, the inhabitant in Dai Son is more sensitive to the 'increased' observation of landslides; or in other words, their perception is more proactive regarding these climateinduced hazards.

\section{Conclusion}

Flash floods and landslides are severe natural disasters in many highly mountainous regions around the world, particularly in areas where strong deforestation occurs. In Vietnam, these events mainly happen in the Northern mountainous regions, one of the country's most impoverished communities. The impacts of flash floods and landslides in this region are pressing issues causing major socio-economic problems, which are even expected to be more severe in the remote areas due to high levels of poverty, poor adaptive capacities and infrastructure, inadequate access to healthcare facilities and technologies, and high dependence on natural resources. Such remote areas challenge the achievements of 
poverty reduction and require sustainable strategies and assistance to adapt to climate change. However, empirical research on how farmers perceive changes in such climate-induced natural disasters still remains limited in the region.

The study aims to explore to what extent the livelihoods of rural farmers in one of the poorest provinces in the Northern region of Vietnam are affected by flash floods and landslides. Besides, since understanding the perception of local people on natural hazards is significant to advise effective supporting policies in the process of promoting the implementation of adaptation measures, we, therefore, sought to determine the factors influencing farmers' perception of these natural hazards. The study reveals that an overwhelming majority of farmers recognized the changes in flash floods and landslides and expressed the negative impacts of flash floods and landslides on their livelihood activities. The most recorded damages in the study area include reducing productivity, decreasing income, more hard-working conditions, increasing daily expenses, causing disease in livestock, poultry, and people, and losing land. These consequences subsequently lead to increasing households' sensitivity and decreasing their adaptive capacity to recover or overcome adverse sequences of natural hazards.

Results from the MNL models suggested that local farmers' perceptions are shaped by both internal (i.e., experience in agriculture, male (gender), ethnic minority group (ethnicity), and poor household (household condition)) and external factors (i.e., distance to market, climate information, and agri-ecological zone). The study's findings are firmly in line with recent studies (Ahmad and Afzal, 2020; Ayal and Leal Filho, 2017; Funatsu et al., 2019; Khan et al., 2020), emphasizing the influence of farmers' socio-economic, psychological, and geographic characteristics on the perception process of smallholder farmers subject to climate variability. Specifically, we found evidence that having one more year experience in agriculture would increase the probabilities $(8.2 \%, 8.0 \%$, and $10.7 \%)$ of perceiving the 'did not change', 'increased', and 'decreased' options in the frequency and impacts of flash floods compared to the 'do not know' option. Furthermore, a higher probability of $4.0 \%$ in recognizing the 'decreased' phenomenon in the frequency and impacts of landslides relative to the "do not know' option are recorded. In addition, the research detected that being a male would significantly increase households' perception. For example, the probability for a man in perceiving the 'did not change' compared to the 'do not know' option in the frequency and impacts of flash floods and landslides is 4.5 times and 6 times higher than for a woman, respectively.

Interestingly, belonging to an ethnic minority group and being a poor household were witnessed to be significantly and positively associated with the perception of changes in the frequency and impacts of flash floods and landslides, as it is characterized by the socio-economic aspects in the study areas that those people in such areas rely more on agriculture and forest rather than the major group (the 'Kinh' people). The regression results pointed out that the probabilities of smallholder farmers in the ethnic minority groups in noticing the 'increased' and 'decreased' relative to the 'do not know' option in the changes of flash floods and landslides are more or equal 10 times and around 6 times higher than the 'Kinh' majority group, correspondingly. While the way individuals perceived changes of these climate-induced events is significantly and negatively related to the distance to market, it is found to be positively associated with the level of information on climate local farmers may receive. For instance, the likelihood of perceiving the 'did not change' and 'increased' option compared to the choice of 'do not know' in the frequency and impacts of flash floods would be reduced $0.8 \%$ for those who live far away from the market one more kilometer. Also, receiving climate information would increase at least 3.5 times in the probability of perceiving changes in both flash flood and landslide events. Meanwhile, level of education, availability of extension services, farm size, farm and non-farm income are found to be insignificantly correlated with the awareness of rural households on flash floods and landslides.

From policy and development strategy perspectives, the findings in this study indicate several important implications to improve the awareness of local people.

- First, building farmers' capacity should be a priority. To do so, the local Government should encourage farmers to participate in social organizations and join vocational training to keep updating new information, as well as fostering their learning process.

- Second, the awareness of people living in different communes are diverse, and their understanding might not be entirely correct, the local Government should have more officials to deliver climate information adequately and frequently, or they can increase the contact with local people using different means. Local Government would also need to improve the effectiveness of the extension agency.

- Third, there are still major gaps in understanding the frequency and impacts of flash floods and landslides between different groups of people, such as between male and female, between experienced people and less experienced fellows, and between ethnic groups. Hence, special programs targeting specific groups of people are needed to improve their awareness and balance the overall understanding of people in the region.

This study was, however, constrained/limited by selecting explanatory factors in the perception models as it only covered several aspects affecting people's perceptions to changes of flash floods and landslides. More specific factors related to economic, political, and social changes may also affect their understanding; however, through the survey, FGDs, and discussions with local officials, we realized that these factors had not changed dramatically recently. Hence, these factors might not significantly affect the results of this study. However, it is still acknowledged as limitations at this stage, and we expect to include in future work not only individual household features but also specific economic, political, and social changes in order to improve the estimations.

Supplementary data to this article can be found online at https://doi. org/10.1016/j.scitotenv.2020.142656.

\section{CRediT authorship contribution statement}

Nga Thanh Thi Pham: Conceptualization, Methodology, Software, Formal analysis, Investigation, Data curation, Writing original draft, Writing - review \& editing. Duy Nong: Conceptualization, Methodology, Formal analysis, Writing - original draft, Writing - review \& editing. Matthias Garschagen: Conceptualization, Methodology, Formal analysis, Writing - original draft, Writing - review \& editing.

\section{Declaration of competing interest}

The authors declare that they have no known competing financial interests or personal relationships that could have appeared to influence the work reported in this paper.

\section{Acknowledgments}

We are very grateful to the Vietnam International Education Cooperation Department and the United Nations University in Bonn, Germany for financing the research. We would like to thank Professor Jakob Rhyner for his supports and guidance, Mrs. Trinh Hao and Mrs. Dao Chiem for helping with data collection, and also thank all interviewees for participating in the survey. 


\section{Appendix A}

The perception model's results are shown in Table 7 (for the perception of flash floods) and Table 8 (for the perception of landslides). The Ordinary Least Square model was fitted, and the model was tested for multicollinearity using the variance inflation factor (VIF). The means of VIF for all variables in both models are 1.31 (range from 1.04 to 1.70 ), which is $<10$, indicating that multicollinearity is not a problem in these models. These models, in addition, were run and tested for the validity of the independence of the irrelevant alternatives (IIA) assumptions by using both the Hausman tests and the Small - Hsiao tests. Both tests failed to reject the null hypothesis of independence of the flash flood and landslide perception choices, presenting that the MNL specification is appropriate to model farmers' perception of changes in the frequency and impacts of flash floods and landslides. Furthermore, the Multinomial Logit Regression models are highly significant at 1 percent level (perception model of flash floods: LR chisquare $(39)=202.06$; Log-likelihood $=-347.79407 ; P>$ chi-square $=0.0000$; Pseudo $R^{2}=0.2251$ and perception model of landslides: LR chisquare $(39)=207.90 ;$ Log-likelihood $=-392.81622 ; P>$ chi-square $=0.0000$; Pseudo $R^{2}=0.2093$ ), suggesting that these models have strongly explanatory powers.

\section{Appendix B}

Table B1

Marginal effects from the MNL of perception on flash floods.

Source: Authors' own estimation.

\begin{tabular}{|c|c|c|c|c|c|c|c|c|}
\hline \multirow[t]{3}{*}{ Variables } & \multicolumn{8}{|l|}{ Perception } \\
\hline & \multicolumn{2}{|c|}{ Did not change } & \multicolumn{2}{|l|}{ Increased } & \multicolumn{2}{|l|}{ Decreased } & \multicolumn{2}{|c|}{ Do not know } \\
\hline & Coefficient & $P>|z|$ & Coefficient & $P>|z|$ & Coefficient & $P>|z|$ & Coefficient & $P>|z|$ \\
\hline \multicolumn{9}{|l|}{ Internal factors } \\
\hline Experience in agriculture & -0.001 & 0.652 & -0.004 & 0.153 & $0.005^{* *}$ & 0.024 & -0.000 & 0.359 \\
\hline Male (gender) & 0.084 & 0.461 & -0.107 & 0.280 & 0.065 & 0.380 & -0.006 & 0.496 \\
\hline Ethnic minority group (ethnicity) & -0.047 & 0.386 & 0.083 & 0.304 & -0.031 & 0.616 & -0.005 & 0.382 \\
\hline Poor household (Household condition) & 0.067 & 0.258 & -0.060 & 0.460 & -0.008 & 0.905 & 0.001 & 0.826 \\
\hline Education level & 0.013 & 0.521 & -0.027 & 0.358 & 0.014 & 0.577 & 0.000 & 0.710 \\
\hline Farm size in ha & -0.007 & 0.629 & -0.015 & 0.291 & $0.022^{* *}$ & 0.029 & -0.001 & 0.473 \\
\hline Farm income & -0.001 & 0.357 & $0.000^{*}$ & 0.351 & $-0.000^{*}$ & 0.995 & -0.000 & 0.367 \\
\hline Non-farm income & -0.000 & 0.974 & -0.000 & 0.760 & 0.001 & 0.766 & 0.000 & 0.380 \\
\hline \multicolumn{9}{|l|}{ External factors } \\
\hline Contact extension services & 0.000 & 0.994 & 0.081 & 0.248 & -0.080 & 0.125 & -0.001 & 0.559 \\
\hline Distance to market & -0.001 & 0.899 & -0.008 & 0.582 & 0.006 & 0.562 & 0.000 & 0.366 \\
\hline Information on weather & $-0.179^{*}$ & 0.072 & 0.039 & 0.732 & $0.146^{* *}$ & 0.039 & -0.006 & 0.489 \\
\hline An Thinh & -0.028 & 0.592 & 0.056 & 0.468 & -0.025 & 0.658 & -0.003 & 0.433 \\
\hline Dai Son & $-0.166^{* * *}$ & 0.000 & $0.635^{* * *}$ & 0.000 & $-0.464^{* * *}$ & 0.000 & -0.005 & 0.356 \\
\hline
\end{tabular}

* Significant at $10 \%$ level.

** Significant at 5\% level.

*** Significant at $1 \%$ level.

Table B2

Marginal effects from the MNL of perception on landslides.

Source: Authors' own estimation.

\begin{tabular}{|c|c|c|c|c|c|c|c|c|}
\hline \multirow[t]{3}{*}{ Variables } & \multicolumn{8}{|l|}{ Perception } \\
\hline & \multicolumn{2}{|c|}{ Did not change } & \multicolumn{2}{|l|}{ Increased } & \multicolumn{2}{|l|}{ Decreased } & \multicolumn{2}{|c|}{ Do not know } \\
\hline & Coefficient & $P>|z|$ & Coefficient & $P>|z|$ & Coefficient & $P>|z|$ & Coefficient & $P>|z|$ \\
\hline \multicolumn{9}{|l|}{ Internal factors } \\
\hline Experience in agriculture & -0.001 & 0.664 & -0.004 & 0.201 & $0.005^{* *}$ & 0.024 & -0.001 & 0.279 \\
\hline Male (gender) & $0.161^{* * *}$ & 0.001 & $-0.207^{* *}$ & 0.038 & 0.093 & 0.228 & -0.047 & 0.329 \\
\hline Ethnic minority group (ethnicity) & -0.078 & 0.169 & 0.102 & 0.254 & 0.038 & 0.595 & $-0.062^{* *}$ & 0.010 \\
\hline Poor household (Household condition) & $0.122^{*}$ & 0.061 & -0.066 & 0.390 & -0.026 & 0.704 & -0.030 & 0.110 \\
\hline Education level & $0.042^{*}$ & 0.059 & -0.032 & 0.278 & -0.008 & 0.765 & -0.002 & 0.805 \\
\hline Farm size in ha & -0.002 & 0.880 & -0.014 & 0.290 & 0.013 & 0.264 & 0.004 & 0.280 \\
\hline Farm income & -0.001 & 0.119 & 0.001 & 0.184 & 0.000 & 0.758 & -0.000 & 0.876 \\
\hline Non-farm income & -0.000 & 0.488 & -0.001 & 0.321 & 0.001 & 0.108 & 0.000 & 0.343 \\
\hline \multicolumn{9}{|l|}{ External factors } \\
\hline Contact extension services & 0.046 & 0.413 & 0.071 & 0.327 & $-0.110^{*}$ & 0.047 & -0.006 & 0.730 \\
\hline Distance to market & -0.012 & 0.211 & 0.001 & 0.964 & 0.012 & 0.246 & -0.001 & 0.749 \\
\hline Information on weather & $-0.287^{* *}$ & 0.005 & 0.127 & 0.188 & $0.294^{* * *}$ & 0.000 & $-0.134^{*}$ & 0.091 \\
\hline An Thinh & 0.103 & 0.124 & $-0.195^{* *}$ & 0.015 & 0.047 & 0.472 & 0.045 & 0.164 \\
\hline Dai Son & $-0.205^{* * *}$ & 0.000 & $0.599^{* * *}$ & 0.000 & $-0.322^{* * *}$ & 0.000 & $-0.073^{* * *}$ & 0.002 \\
\hline
\end{tabular}

* Significant at $10 \%$ level.

** Significant at 5\% level.

*** Significant at $1 \%$ level. 


\section{References}

Abid, M., Scheffran, J., Schneider, U.A., Elahi, E., 2019. Farmer perceptions of climate change, observed trends and adaptation of agriculture in Pakistan. Environ. Manag. 63, 110-123. https://doi.org/10.1007/s00267-018-1113-7.

Adger, W. N., 2003. Social capital, collective action, and adaptation to climate change. Econ. Geogr.327-345. doi:https://doi.org/10.1007/978-3-531-92258-4_19

Adger, W. Neil, Vincent, K., 2005. Uncertainty in adaptive capacity. Compt. Rendus Geosci. 337 (4), 399-410. https://doi.org/10.1016/j.crte.2004.11.004.

Adger, W. Neil, Dessai, S., Goulden, M., Hulme, M., Lorenzoni, I., Nelson, D. R., Wreford, A., 2009. Are there social limits to adaptation to climate change? Climatic. Change. 93 (3-4), 335-354. doi:https://doi.org/10.1007/s10584-008-9520-z.

Agho, Kingsley, Stevens, Garry, Taylor, Mel, Barr, Margo, Raphael, Beverley, 2010. Population risk perceptions of global warming in Australia. Environ. Res. 110, 756-763. https://doi.org/10.1016/j.envres.2010.09.007.

Ahmad, D., Afzal, M., 2020. Flood hazards and factors influencing household flood perception and mitigation strategies in Pakistan. Environ. Sci. Pollut. R. 27, 15375-15387. https://doi.org/10.1007/s11356-020-08057-z.

Amadou, M.L., Villamor, G.B., Attua, E.M., 2015. Comparing farmers' perception of climate change and variability with historical climate data in the Upper East Region of Ghana. Ghana J. Geogr. 7 (1), 47-74.

Ayal, D.Y., Leal Filho, W., 2017. Farmers' perceptions of climate variability and its adverse impacts on crop and livestock production in Ethiopia. J. Arid Environ. 140, 20-28. https://doi.org/10.1016/j.jaridenv.2017.01.007.

Below, T.B., Mutabazi, K.D., Kirschke, D., Franke, C., Sieber, S., Siebert, R., Tscherning, K., 2011. Can farmers' adaptation to climate change be explained by socio-economic household-level variables? Glob. Environ. Chang. 22, 223-235. https://doi.org/ 10.1016/j.gloenvcha.2011.11.012.

CARE, 2013. Climate vulnerability and capacity of ethnic minorities in the northern mountainous region of Viet Nam. Retrieved from. http://www.care.org/sites/default/files/documents/CC-2013-VNM-CARE_ClimChg_Vietnam.pdf.

Cullen, A.C., Anderson, C.L., 2016. Perception of climate risk among rural farmers in Vietnam: consistency within households and with the empirical record. Risk Anal. 37, 531-545. https://doi.org/10.1111/risa.12631.

Das, H.P., 2005. Agrometeorological impact assessment of natural disasters and extreme events and agricultural strategies adopted in areas with high weather risks. In: Sivakumar, M.V., Motha, R.P., Das, H.P. (Eds.), Natural Disasters and Extreme Events in Agriculture, pp. 93-118 https://doi.org/10.1007/3-540-28307-2_6.

Debela, N., Mohammed, C., Bridle, K., Corkrey, R., McNeil, D., 2015. Perception of climate change and its impact by smallholders in pastoral/agropastoral systems of Borana, South Ethiopia. SpringerPlus 4 (1). https://doi.org/10.1186/s40064-015-1012-9.

Deressa, T., 2009. Determinants of farmers' choice of adaptation methods and perceptions of climate change in the Nile Basin of Ethiopia. Glob. Environ. Change. 19, 248-255.

Deressa, T., Hassan, R.M., Ringler, C., 2009. Assessing household vulnerability to climate change: the case of farmers in the Nile Basin of Ethiopia. IFFRI Discussion Paper, p. 935.

Deschenes, O., Greenstone, M., 2007. The economics impacts of climate change: evidence from agricultural output and random fluctuations in weather. Am. Econ. Rev. 97, 354-385.

Do, T., Nguyen, C., Phung, T., 2013. Assessment of natural disasters in Vietnam's Northern Mountains. MPRA Paper No. 54209. https://mpra.ub.uni-muenchen.de/id/eprint/ 54209.

FAO, 2015. The Impact of Natural Hazards and Disasters on Agriculture and Food Security and Nutrition.

Funatsu, B.M., Dubreuil, V., Racapé, A, Debortoli, N.S, Nasuti, S. Le Tourneau, F.M., 2019. Perceptions of climate and climate change by Amazonian communities. Glob. Environ. Chang. 57, 101923. https://doi.org/10.1016/j.gloenvcha.2019.05.007.

Funk, C., Raghavan Sathyan, A., Winker, P., Breuer, L., 2020. Changing climate - changing livelihood: smallholder's perceptions and adaption strategies. J. Environ. Manag. 259, 109702. https://doi.org/10.1016/j.jenvman.2019.109702.

Gandure, S., Walker, S., Botha, J.J., 2013. Farmers' perceptions of adaptation to climate change and water stress in a South African rural community. Environ. Dev. 5, 39-53. https://doi.org/10.1016/j.envdev.2012.11.004.

Gbetibouo, G.A., 2009. Understanding farmers' perceptions and adaptations to climate change and variability: the case of the Limpopo basin. South Africa. IFPRI Discussion Paper, South Africa, p. 849 https://doi.org/10.1068/a312017.

Grothmann, T., Patt, A., 2005. Adaptive capacity and human cognition: the process of individual adaptation to climate change. Glob. Environ. Chang. 15, 199-213. https://doi. org/10.1016/j.gloenvcha.2005.01.002.

Hansen, J., Marx, S., Weber, E., 2004. The Role of Climate Perceptions, Expectations, and Forecasts in Farmer Decision Making. International Research Institute for Climate Prediction (IRI).

Hasan, K., Kumar, L., 2019. Comparison between meteorological data and farmer perceptions of climate change and vulnerability in relation to adaptation. J. Environ. Manag. 237, 54-62. https://doi.org/10.1016/j.jenvman.2019.02.028.

Hasan, K., Kumar, L., 2020. Meteorological data and farmers' perception of coastal climate in Bangladesh. Sci. Total Environ. 704, 135384. https://doi.org/10.1016/j. scitotenv.2019.135384.

Huda, M.N., 2013. Understanding indigenous people's perception on climate change and climatic hazards: a case study of Chakma indigenous communities in Rangamati Sadar Upazila of Rangamati District. Bangladesh. Nat. Hazards. 65, 2147-2159. https://doi.org/10.1007/s11069-012-0467.

IPCC, 2018. Summary for policymakers. Global Warming of $1.5^{\circ} \mathrm{C}$ : An IPCC Special Report on the Impacts of Gloable Warming of 1.5 Above Pre-industrial Levels and Related Global Greenhouse Gas Emission Pathways, in the Context of Strengthening the Global
Response to the Threat of Clinate Change, Sustainable Development, and Efforts to Eradicate Poverty. World Meteorological Organization, Geneva, Switzerland (32pp.).

Jost, C., Kyazze, F., Naab, J., Neelormi, S., Kinyangi, J., Zougmore, R., Kristjanson, P., 2015. Understanding gender dimensions of agriculture and climate change in smallholder farming communities. Clim. Dev. 8, 133-144. https://doi.org/ 10.1080/17565529.2015.1050978.

Kates, R.W., 2000. Cautionary tales: adaptation and the global poor. Clim. Chang. 45, 5-17.

Khan, N.A., Gao, Q., Iqbal, M.A., Abid, M., 2020. Modeling food growers' perceptions and behavior towards environmental changes and its induced risks: evidence from Pakistan. Environ. Sci. Pollut. R. 27, 20292-20308. https://doi.org/10.1007/s11356020-08341-y.

Kurukulasuriya, P., Mendelsohn, R., 2006. Crop selection: adapting to climate change in Africa. CEEPA Discussion Paper 26, 1-29.

Le Dang, H., Li, E., Bruwer, J., Nuberg, I., 2014. Farmers' perceptions of climate variability and barriers to adaptation: lessons learned from an exploratory study in Vietnam. Mitig. Adapt. Strat. Gl. 19, 531-548. https://doi.org/10.1007/s11027-012-9447-6.

Liverpool-Tasie, L.S.O., Pummel, H., Tambo, J.A., Olabisi, L.S., Osuntade, O., 2020. Perceptions and exposure to climate events along agricultural value chains: evidence from Nigeria. J. Environ. Manag. 264, 110430. https://doi.org/10.1016/j.jenvman.2020.110430.

Maddison, D., 2006. The perception of and adaptation to climate change in Africa (Centre for Environmental Economics and Policy in Africa). Policy Research Working Paper. p. 4308 https://doi.org/10.1007/s13398-014-0173-7.2.

Marconi, M., Marincioni, F., Tran, V.G.P., 2011. Strengthening Capacities to Enhance Coordinated and Integrated Disaster Risk Reduction Actions and Adaptation to Climate Change in Agriculture in the Northern Mountain Regions of Vietnam: Hazard, Vulnerability and Risk Mapping in. Lao Cai, Yen Bai and Phu Tho.

Marx, S.M., Weber, E.U., Orlove, B.S., Leiserowitz, A., Krantz, D.H., Roncoli, C., Phillips, J., 2007. Communication and mental processes: experiential and analytic processing of uncertain climate information. Glob. Environ. Chang. 17, 47-58. https://doi.org/ 10.1016/j.gloenvcha.2006.10.004.

Mendelsohn, R., 2008. The impact of climate change on agriculture in developing countries. Journal of Natural Resources Policy Research 1 (1), 5-19. https://doi.org/ 10.1080/19390450802495882.

Mitter, H., Larcher, M., Schönhart, M., Stöttinger, M., Schmid, E., 2019. Exploring farmers climate change perceptions and adaptation intentions: empirical evidence from Austria. Environ. Manag. 63, 804-821. https://doi.org/10.1007/s00267-019-01158-7.

MONRE, 2017. National Disaster Risk in Viet Nam in the Period 2006-2016 and Forecasting and Warning System.

Nhemachena, C., Hassan, R., 2008. Micro-level analysis of farmers' adaptation to climate change in Southern Africa. IFPRI Discussion Paper, p. 714 https://doi.org/10.1017 S1742170512000257.

Pan, Anping, 2016. Study on mobility-disadvantage group' risk perception and coping behaviors of abrupt geological hazards in coastal rural area of China. Environ. Res. 148, 574-581. https://doi.org/10.1016/j.envres.2016.04.016.

Pham, T.H., Le, D.T., Nguyen, V.C., 2010. Poverty of the ethnic minorities in Vietnam: situation and challenges from the poorest communes. MPRA (Munich Personal RePEc Archive) Paper, p. 50372.

Pham, N.T.T., Nong, D., Garschagen, M., 2019. Farmers' decisions to adapt to flash floods and landslides in the Northern Mountainous Regions of Vietnam. J. Environ. Manag. 252, 109672. https://doi.org/10.1016/j.jenvman.2019.109672.

Pham, N.T.T., Nong, D., Raghavan Sathyan, A., Garschagen, M., 2020. Vulnerability assessment of households to flash floods and landslides in the poor upland regions of Vietnam. Clim. Risk Manag. 28, 100215. https://doi.org/10.1016/j.crm.2020.100215.

Poortinga, W., Whitmarsh, L., Steg, L., Böhm, G., Fisher, S., 2019. Climate change perceptions and their individual-level determinants: a cross European analysis. G Glob. Environ. Chang. 55, 23-35. https://doi.org/10.1016/j.gloenvcha.2019.01.007.

Porter, J.R., Xie, L., Challinor, A.J., Cochrane, K., Howden, S.M., Iqbal, M.M., Lobell, D.B., Travasso, M.I., 2014. Food security and food production systems. Climate Change 2014: Impacts, Adaptation, and Vulnerability. Part A: Global and Sectoral Aspects. Contribution of Working Group II to the Fifth Assessment Report of the Intergovernment Panel on Climate Change. Cambridge University Press, Cambridge, United Kingdom and New York, NY, USA, pp. 485-533.

Roco, L., Engler, A., Bravo-Ureta, B.E., Jara-Rojas, R., 2014. Farmers' perception of climate change in mediterranean Chile. Reg. Environ. Chang. 15, 867-879.

Rosaine, N.Y., 2014. Adaptation to Climate Change and Sustainable Agriculture in West Africa: A Case Study of Maize Farming in Benin. Giessen University.

Santoro, S., Pluchinotta, I., Pagano, A., Pengal, P., Cokan, B., Giordano, R., 2019. Assessing stakeholders' risk perception to promote Nature Based Solutions as flood protection strategies: the case of the Glinščica river (Slovenia). Sci. Total Environ. 655, 188-201. https://doi.org/10.1016/j.scitotenv.2018.11.11.

Semenza, Jan C., Wilson, Daniel J., Parra, Jeremy, Bontempo, Brian D., Hart, Melissa, Sailor, David J., George, Linda A., 2008. Public perception and behavior change in relationship to hot weather and air pollution. Environ. Res. 107, 401-411. https://doi.org/ 10.1016/j.envres.2008.03.005.

Sharma, A., Batish, D.R., Uniyal, S.K., 2020. Documentation and validation of climate change perception of an ethnic community of the western Himalaya. Environ. Monit. Assess. 192. https://doi.org/10.1007/s10661-020-08512-X.

Silvestri, S., Bryan, E., Ringler, C., Herrero, M., Okoba, B., 2012. Climate change perception and adaptation of agro-pastoral communities in Kenya. Reg. Environ. Chang. 12, 791-802. https://doi.org/10.1007/s10113-012-0293-6.

Singh, R.K., Singh, A., Kumar, S., Sheoran, P., Sharma, D.K., Stringer, L.C., Singh, D., 2020 Perceived climate variability and compounding. implications for risks to livelihoods of smallholder indian farmers. Environ. Manage, stressors https://doi.org/10.1007/ s00267-020-01345-X. 
Tesfahunegn, G.B., Mekonen, K., Tekle, A., 2016. Farmers' perception on causes, indicators and determinants of climate change in northern Ethiopia: implication for developing adaptation strategies. Appl. Geogr. 73, 1-12. https://doi.org/10.1016/j.apgeog.2016.05.009.

Tran, V.S., Boyd, W., Slavich, P., Van Trinh, M., 2015. Perception of climate change and farmers' adaptation: a case study of poor and non-poor farmers in northern central coast of Vietnam. J. Basic Appl. Sci. 11, 323-342. https://doi.org/10.6000/19275129.2015.11.48.

Waibel, H., Pahlisch, T.H., Völker, M., 2018. Farmers' perceptions of and adaptations to climate change in Southeast Asia: the case study from Thailand and Vietnam. Nat. Res. Man. 52, 137-160. https://doi.org/10.1007/978-3-319-61194-5.

Weber, E.U., 2010. What shapes perceptions of climate change? Wiley Interdisciplinary Reviews: Clim. Change. 1, 332-342. https://doi.org/10.1002/wcc.41.
Wooldridge, J.M., 2010. Econometric Analysis of Cross Section and Panel Data. The MIT Press Cambridge, Massachusetts London, England. https://doi.org/10.1007/ s007690000247.

World Bank, 2017. Climate Risk and Adaptation Country. Vulnerability, Risk Reduction, and Adaptation to Climate Change in Vietnam, Profile https://doi.org/10.1001/ jama.2014.13094

Young, G., Valdez, E.A., Kohn, R., 2009. Multivariate probit models for conditional claim-types Insur. Mat. Econ. 44, 214-228. https://doi.org/10.1016/j.insmatheco.2008.11.004.

Zamasiya, B., Nyikahadzoi, K., Mukamuri, B.B., 2017. Factors in fluencing smallholder farmers' behavioural intention towards adaptation to climate change in transitional climatic zones: a case study of Hwedza District in Zimbabwe. J. Environ. Manag. 198, 233-239. https://doi.org/10.1016/j.jenvman.2017.04.073. 